\title{
Aberrant synchrony of present-day warming
}

Were extended warm or cold periods in the past worldwide, or only regional? Efforts to reconstruct Earth's climate history suggest that the near-global extent of ongoing warming is unparalleled over the past 2,000 years. SEE LETTER P.550

\section{SCOTT ST. GEORGE}

$\mathrm{T}$ The history of Earth's climate is punctuated by a succession of named intervals associated with prolonged shifts to warmer, colder, wetter or drier conditions. During the Common Era (the past 2,000 years), the two best-known such climate epochs are the Little Ice Age $^{1}$ and the Medieval Climate Anomaly ${ }^{2}$ (also called the Medieval Warm Period; Fig. 1). The former was a cool period that extended from the sixteenth to the late nineteenth centuries; the latter was a warm, dry period between AD 950 and 1250. Many assume that these intervals had a global impact. But on page 550 of this issue ${ }^{3}$ and in a companion paper in Nature Geoscience, Neukom et al. demonstrate that these and earlier climate epochs in the Common Era were much smaller in scope than the near-global reach of current human-induced warming.

Because thermometer measurements of air near Earth's surface before AD 1850 are not widely available, we rely on archives of proxy data to extend our perspective on climate further back in time. Trees in cold Arctic or alpine forests have annual rings with widths and wood densities that reflect year-to-year variations in summer temperature ${ }^{5}$. And because the chemical make-up of seawater depends on its temperature, massive corals build endoskeletons that contain a permanent geochemical record of past warming and cooling $^{6}$. Other geological and biological archives that encode temperature information into their physical structure, substance or geochemical composition include lake sediments, glacier ice and bivalve molluscs (such as clams, oysters and mussels). Such archives likewise serve as 'palaeothermometers' that record temperatures stretching hundreds or thousands of years into the past.

Neukom et al. weave all of this evidence into a detailed global portrait of surface temperatures that spans the past two millennia. The foundation for their work is provided by the PAGES $2 \mathrm{k}$ proxy temperature database ${ }^{7}$. This community-sourced compilation includes nearly 700 records from trees, ice, sediment, corals, cave deposits, documentary evidence and other archives. Partly because the database incorporates so much information, the authors can chart the geographical extent of unusually warm or cold conditions across the entire planet by year.

The team reports in Nature that, although the Little Ice Age was the coldest epoch of the past millennium, the timing of the lowest temperatures varied from place to place. Twofifths of the planet were subjected to the coldest weather during the mid-nineteenth century, but the deepest chill occurred several centuries earlier in other regions. And even at the height of the Medieval Climate Anomaly, only $40 \%$ of Earth's surface reached peak temperatures at the same time. Using the same metrics, global warming today is unparalleled: for $98 \%$ of the planet's surface, the warmest period of the Common Era occurred in the late twentieth century - the authors' analysis does not encompass the continued warming in the early twenty-first century, because many of their proxy records were collected more than two decades ago.

In 2005, palaeoclimatologists John Matthews and Keith Briffa ${ }^{1}$ cautioned against deeming the Little Ice Age an "uninterrupted, globally synchronous, cold period". These new results certainly bolster their point of view. And we can be confident in that conclusion because Neukom et al. carried out an exhaustive set of experiments to confirm that their findings were unaffected by their choice of statistical tools to relate the proxy network to thermometer measurements.

Unfortunately, limitations inherent in the proxies themselves probably still hamper our ability to compare warm or cool intervals with each other throughout the entire Common Era. Tree-ring records, the most frequently used proxy archive in the PAGES 2k database, are sometimes unreliable in registering slow climate changes over several centuries or longer ${ }^{8}$. Moreover, some other proxies - particularly records from marine and lake sediments - exaggerate variations at multidecadal or centennial timescales ${ }^{9,10}$. It is still an open question how well we can compare global temperatures across this entire 2,000-year span.

We can be more certain of how and why Earth warms or cools over decadal and multidecadal timescales. In their companion paper in Nature Geoscience, Neukom et al. show that, in the pre-industrial period (AD 1300-1800),

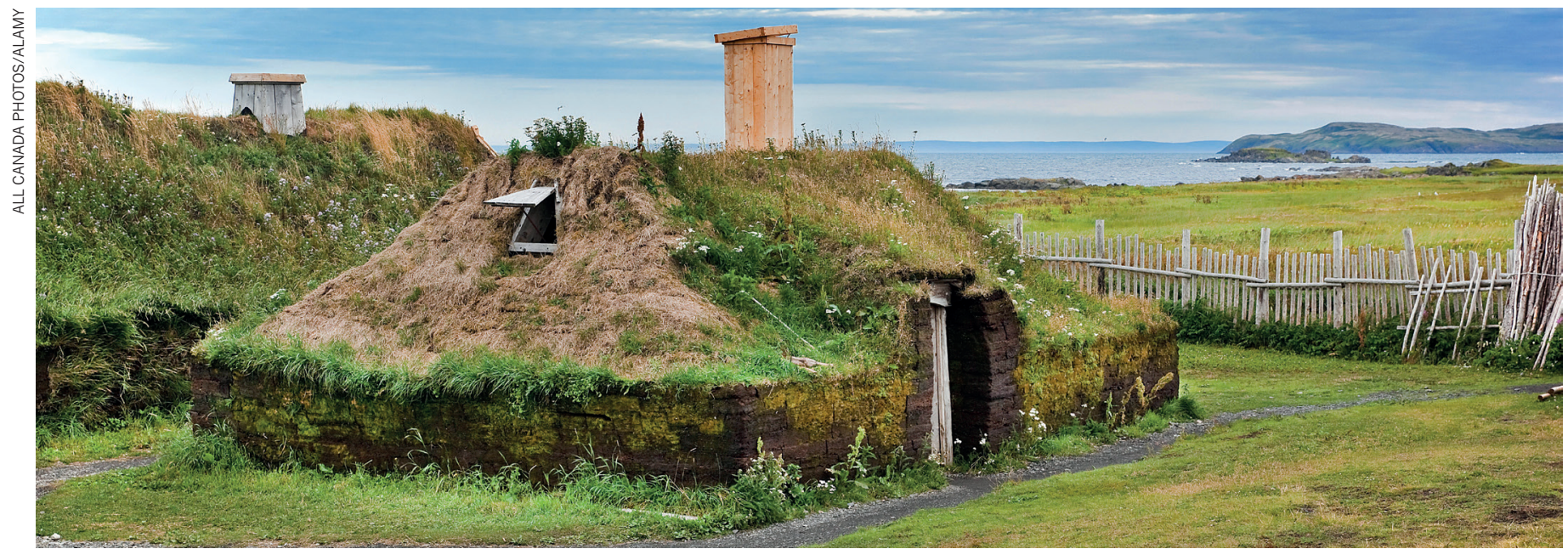

Figure 1 | Evidence of medieval warmth. Unusually warm weather between the tenth and thirteenth centuries is often cited as one factor that enabled the short-lived Norse colonization of the Americas. Shown here are reconstructed buildings at a site called L'Anse aux Meadows in Newfoundland, Canada - a
Norse settlement that was established in the early eleventh century. Neukom et al. ${ }^{3,4}$ have constructed a set of pre-industrial temperature estimates, and find that past warm and cold periods were much less geographically widespread than is the current warming caused by humans. 
major volcanic eruptions (or the lack of such eruptions) were the main factor behind cold (or warm) swings that persisted for several decades. Shifts in greenhouse-gas concentrations had a smaller, but still detectable, imprint. The team found no indication that variations in the Sun's radiation output affected mean global temperature over the same time frames.

In general, physics-based climate models accurately reproduce proxy estimates of our climate's history over the past millennium. However, these models exaggerate the degree of cooling caused by the two largest volcanic eruptions of the Common Era: the AD 1257 Samalas and the AD 1815 Tambora eruptions in Indonesia $^{11}$. This discrepancy implies that we cannot be sure how bitter a chill would follow a similar eruption in the future.

The familiar maxim that the climate is always changing is certainly true. But even when we push our perspective back to the earliest days of the Roman Empire, we cannot discern any event that is remotely equivalent either in degree or extent - to the warming over the past few decades. Today's climate stands apart in its torrid global synchrony.

Scott St. George is in the Department of Geography, Environment and Society, University of Minnesota, Minneapolis, Minnesota 55455, USA.

e-mail:stgeorge@umn.edu
1. Matthews, J. A. \& Briffa, K. R. Geogr. Ann. A 87, 17-36 (2005).

2. Mann, M. E. et al. Science 326, 1256-1260 (2009).

3. Neukom, R., Steiger, N., Gómez-Navarro, J. J., Wang, J. \& Werner, J. P. Nature 571, 550-554 (2019).

4. PAGES 2 k Consortium. Nature Geosci. https://doi. org/10.1038/s41561-019-0400-0 (2019).

5. Esper, J. et al. Dendrochronologia 50, 81-90 (2018).

6. Tierney, J. E. et al. Paleoceanography 30, 226-252 (2015).

7. PAGES2k Consortium. Sci. Data 4, 170088 (2017).

8. Cook, E. R., Briffa, K. R., Meko, D. M., Graybill, D. A. \& Funkhouser, G. Holocene 5, 229-237 (1995).

9. McGregor, H. V. et al. Nature Geosci. 8, 671-677 (2015).

10. Huybers, K., Rupper, S. \& Roe, G. H. Clim. Dyn. 46, 3709-3723 (2016).

11.Sigl, M. et al. Nature 523, 543-549 (2015).

\section{Cell communication in the blink of an eye}

The bodies of unicellular organisms called protists can contract extremely fast. Analysis reveals that the flow of surrounding fluid during contraction triggers a chain reaction of contraction of neighbouring protists. SEE LETTER P.560

\section{PAVEL TOMANCAK}

$\mathrm{P}$ assing information reliably and rapidly across large distances is crucial for the survival of cells in complex environments. Multicellular organisms have evolved ways to pass signals along neurons at speeds of 100 metres per second. In the unicellular world, organisms rely on their external medium when transmitting signals between cells. Mathijssen et al. ${ }^{1}$ report on page 560 that when unicellular organisms called protists undergo rapid cellular contraction, the fluid in which the organisms live is stirred up, and the resulting fluid flow can trigger the ultra-fast propagation of contraction behaviour across the protist population. Contraction can be accompanied by the release of toxins as a form of defence ${ }^{2}$. The ability to trigger a population-level wave of contractions might be crucial for survival of protists in a perilous aquatic environment full of predators.

The hero of our story is a protist called Spirostomum ambiguum (Fig. 1). Although small by our standards, its length of $1.3 \mathrm{~mm}$ makes it a giant among unicellular organisms. Ever since the biologist Ernst Haeckel reported classic studies of protists in the late nineteenth century ${ }^{3}, S$. ambiguum has been a topic of fascination, particularly because it can contract to about $40 \%$ of its original length at a speed 100 times faster than the blink of an eye $e^{4,5}$. Although biologists have come a long way towards understanding the cellular and molecular mechanisms underlying this contraction $^{6-8}$, it has remained a relatively neglected subject in biological research.

Now Mathijssen and colleagues have explored this topic from a biophysical viewpoint, and their results remind us of how incredibly fast this process is. Using high-speed video microscopy that can capture 10,000 frames per second, the authors filmed the contractions of thousands of S. ambiguum cells, and quantified their contraction speeds comprehensively.

They find that, during its 5-millisecond contraction, the protist accelerates to reach the equivalent of a gravitational force ( $g$ force) of $14 \mathrm{~g}$. This is highly impressive, considering that pilots in the Master Class group of the Red Bull Air Race (a Formula One racing equivalent for aeroplanes) are disqualified if they exceed $12 g$, because a pilot who experiences such forces is at risk of losing consciousness. Yet such $g$ forces pose no problems for S. ambiguum. After the rapid contraction, the protist relaxes comparatively slowly, within about 1 second, and can repeat the cycle again and again.

After quantifying the key parameters of the contraction, Mathijssen and colleagues studied

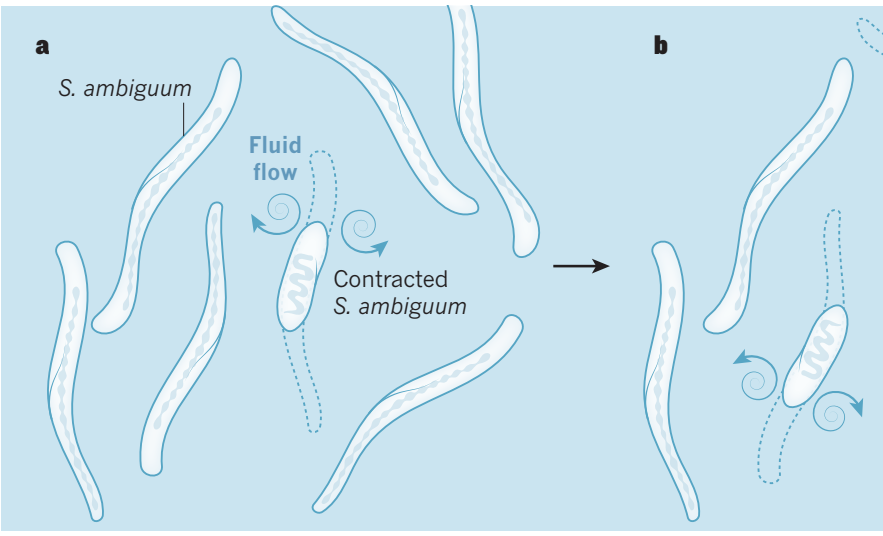

Figure 1 | The spread of a wave of contraction across a protist population. a, The protist Spirostomum ambiguum lives in aquatic environments and has the capacity to contract to less than half its normal length ${ }^{4,5}$. Mathijssen et al. ${ }^{1}$ studied this phenomenon, and report that when this

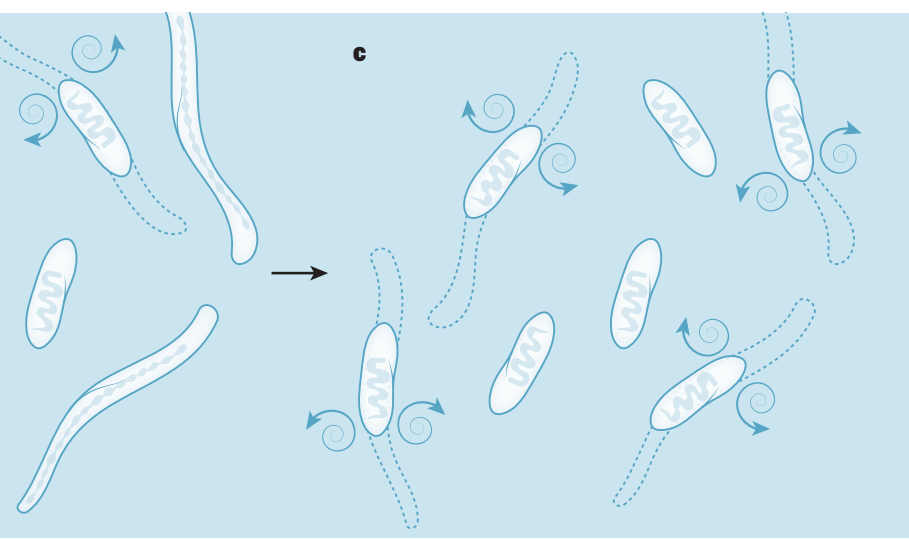

five-millisecond contraction occurs, it generates flows in the surrounding fluid. b. If these flows are sensed by neighbouring S. ambiguum cells, this causes them to contract. c, The contraction can thus rapidly spread through the cell population. 